\title{
Changes of Necroptosis in Irbesartan Medicated Cardioprotection in Diabetic Rats
}

\author{
Qingmei $X u^{\prime}$ \\ Xin $\operatorname{Tan}^{\prime}$ \\ Wei Xian' \\ Jiayi Geng ${ }^{2}$ \\ Haoyu $\mathrm{Li}^{3}$ \\ Bi Tang ${ }^{1,4}$ \\ Heng Zhang' \\ Hongju Wang ${ }^{1,4}$ \\ Qin Gao \\ Pinfang Kang ${ }^{1,4}$ \\ 'Department of Cardiology, The First \\ Affiliated Hospital of Bengbu Medical \\ College, Bengbu, Anhui, 233004, People's \\ Republic of China; ${ }^{2}$ Department of \\ Preventive Medicine, Bengbu Medical \\ College, Bengbu, Anhui, 233000, People's \\ Republic of China; ${ }^{3}$ Clinic Medical \\ College of AnHui Medical University, \\ Hefei, Anhui, 230000, People's Republic \\ of China; ${ }^{4}$ Cardiovascular Disease \\ Research Center of Bengbu Medical \\ College, Bengbu, Anhui, 233030, People's \\ Republic of China; ${ }^{5}$ Department of \\ Physiology, Bengbu Medical College, \\ Bengbu, Anhui, 233000, People's Republic \\ of China
}

Background: Diabetic cardiomyopathy (DCM) is strongly linked to microvascular disease, renin-angiotensin system (RAS) activation, cardiac inflammation and cell apoptosis. Irbesartan is an angiotensin II (Ang II) receptor antagonist in RAS system, which inhibited the conversion of Ang I into Ang II, while the specific mechanism is still obscure.

Objective: This study aims to investigate the expressions necroptosis RIP1-RIP3-MLKL pathway in myocardium of diabetic rats, and the protective action of irbesartan on myocardial damage. Materials and Methods: In our study, 30 Sprague-Dawley rats were divided into 5 groups: CON4W, high glucose and high caloric (HC4W), diabetes mellitus 4 weeks (DM4W group), diabetes mellitus 8 weeks (DM8W group), and irbesartan diabetes 8 weeks (Ir DM8W group).

Results: We discovered that as diabetes progresses, the rats gradually lost weight, the HW/ BW ratio were increased gradually, and the cardiac function became worse accompanied with the aggravation of inflammatory injury. Meanwhile, the myocardial fibers and cells were disordered, and the expression of positive substances, RIP1 and RIP3 increased significantly. The mRNA and protein levels of myocardial RIP1, RIP3 and MLKL were all increased with the progression of DM. After the intervention of irbesartan in diabetic rats, the cardiac function was improved, whereas inflammatory injury and HW/BW ratio were decreased. Also, the myocardial fibrosis injury was attenuated, and the PAS positive substances, RIP1 and RIP3 were significantly decreased. The curative effect of irbesartan was related to decreased myocardial RIP1, RIP3 and MLKL mRNA and protein levels.

Conclusion: In conclusion, irbesartan has a cardioprotective effect on the diabetic rats, and its mechanism may be connected with inhibition of RIP1-RIP3-MLKL pathway.

Keywords: cardiomyocyte, high glucose, irbesartan, inflammatory, necroptosis

\section{Introduction}

Diabetes is associated with cardiac structure and function abnormalities, and the resulting diabetic cardiomyopathy (DCM) is caused by cardiomyocyte hypertrophy and deposition of myocardial collagen fibers, which can eventually lead to cardiac dysfunction and even death. ${ }^{1-3}$ It is closely related to renin-angiotensin system (RAS) activation, microvascular disease, oxidative damage, cardiac inflammation, fibrosis, and apoptosis. ${ }^{3-7}$ Ibesartan has been reported to prevent myocardial damage in diabetic rats, ${ }^{8}$ however, whether irbesartan can prevent the occurrence of myocardial tissue necrosis has not been reported.

A large number of animal models and clinical trials have shown that inhibition of RAS system can effectively alleviate diabetic nephropathy ( $\operatorname{Scr}<265 \mathrm{umol} / \mathrm{L})$ and retinal disease. ${ }^{9,10}$ Ibesartan, as a receptor antagonist of Angiotensin II (Ang II), inhibits the conversion of Angi to Ang II, and inhibited vasoconstriction and
Department of Cardiology, The First Affiliated Hospital of Bengbu Medical College, Bengbu, Anhui, 233004, People's Republic of China

Tel +86552-3086107

Email kangpinfang.1016@163.com 
aldosterone release, it has a good clinical effect on patients with hypertension complicated with diabetic nephropathy and patients with end-stage heart failure of diabetic nephropathy. ${ }^{11}$ Recent studies have shown that irbesartan alleviates inflammatory response and apoptosis through inhibiting NF-kB expression in high glucose-induced H9C2 cells injury, it may also reduce myocardial fibrosis in diabetic rats through MMPs related pathway. ${ }^{11,12}$ Therefore, Ibesartan may have been involved in tissue damage inflammation, apoptosis and other pathological processes through some pathways.

RIP1-RIP3-MLKL pathway is the typical necroptosis pathway. This pathway is involved in inflammatory reaction, ischemia-reperfusion injury, oxidative stress, tumor proliferation and other processes. ${ }^{13,14}$ In 2018, Mompeán et al found MLKL was a specific substrate protein of RIP3, which initially formed the embryonic form of TNF a-guided RIP1-RIP3-MLKL pathway. ${ }^{15}$ Some scholars have shown that the atypical procedural necroptosis pathway RIP3-CaMKII is involved in the diabetic myocardial injury. ${ }^{16} \mathrm{Xu}$ et al discovered which the expression of MLKL was increased in obese mice, especially in liver. ${ }^{17}$ From the above background, we hypothesize that irbesartan may alleviate myocardial damage in diabetic rats, which is related to the RIP1-RIP3-MLKL signal pathway. To test this hypothesis, we investigated the role of irbesartan in a diabetic model and determine its underlying mechanisms.

\section{Materials and Methods}

\section{Chemicals and Materials}

All male Sprague-Dawley rats (130-150 g) were supplied by Bengbu Medical College Animal Center, Anhui Province, China (SCXK20190003). All rats have free access to food and water after a 12-hours light-dark cycle at $22 \pm 2{ }^{\circ} \mathrm{C}$ and $50-70 \%$ humidity. All procedures are performed in accordance with the U.S. Guide for the Care and Welfare of Laboratory Animals. Ibesartan (Sanofi, France), streptozotocin (STZ [Sigma, USA]). Through preliminary experiments, the appropriate treatment dose of Irbesartan was determined. RIP1, RIP3, MLKL and $\beta$-actin antibodies were acquired from Abcam (Cambridge, UK). RIP1, RIP3, MLKL and $\beta$ actin primers were acquired from Sangon Biotech Co., Ltd. (Shanghai, China) (Table 1). ELISA kits for Rat tumor necrosis factor- $\alpha$ (TNF- $\alpha$ ) and interleukin-6 (IL-6) measurement were from Dakewe Biotech Co., Ltd (Shenzhen, China).

\section{Animals and Groups}

$30 \mathrm{SD}$ rats were randomly divided into normal control group (CON), high glucose and high fat group (HC) and diabetes group. The control group was given routine feed. Rats in other groups were fed a high sugar and high fat diet. After 4 weeks, a single intraperitoneal injection of STZ $30 \mathrm{mg} / \mathrm{kg}$ was used to establish the diabetes model in the experimental group. The diabetic model group were randomly assigned to diabetic group (DM) and irbesartan + diabetes group $(\mathrm{Ir}+\mathrm{DM})$. Rats in $\mathrm{Ir}+\mathrm{DM}$ group were given irbesartan $50 \mathrm{mg} / \mathrm{kg} / \mathrm{d}$ intragastrically for 4 weeks and 8 weeks, and then $\mathrm{Ir}+\mathrm{DM} 8 \mathrm{~W}$ groups was obtained in this experiment, the random blood glucose concentration continued to $b e \geq 16.7 \mathrm{mmol} / \mathrm{L}$, indicating the diabetes model has been successfully constructed. FBG was maintained at a high level in the DM4W group, DM8W group and Ir + DM8W group, indicating abnormal lipid metabolism in diabetic rats and successful replication in diabetic models based on hyperlipidemia. There was no significant difference beteween CON4W, CON8W, HC4W and

Table I The Gene Sequences for Different Primers

\begin{tabular}{|l|l|l|l|}
\hline Gene & Primer & Sequence & Product (bp) \\
\hline RIPI & $\begin{array}{l}\text { Forward } \\
\text { Reverse }\end{array}$ & $\begin{array}{l}\text { 5'-AGGTACAGGAGTTTGGTATGGGC-3' } \\
\text { 5'-GGTGGTGCCAAGGAGATGTATG-3' }\end{array}$ & 123 \\
\hline RIP3 & $\begin{array}{l}\text { Forward } \\
\text { Reverse }\end{array}$ & $\begin{array}{l}\text { 5'-TAGTTTATGAAATGCTGGACCGC-3' } \\
\text { 5'-GCCAAGGTGTCAGATGATGTCC-3' }\end{array}$ & 145 \\
\hline MLKL & $\begin{array}{l}\text { Forward } \\
\text { Reverse }\end{array}$ & $\begin{array}{l}\text { 5'-GCCACTGGAAAGATCCCGTT-3' } \\
\text { 5'-CAACAACTCGGGGCAATCCT-3' }\end{array}$ & 108 \\
\hline -actin & $\begin{array}{l}\text { Forward } \\
\text { Reverse }\end{array}$ & 5'-AGACCTTCAACACCCCAG-3' & 156 \\
\hline
\end{tabular}


HC8W, so we chosed CON4W and HC4W as CON and $\mathrm{HC}$ groups.

\section{Echocardiography}

Animals were anesthetized with 3\% isoflurane (Baxter International, USA), lying supine on a heat pad at 37 degrees Celsius (FUJIFILM VisualSonics, Canada). ${ }^{8}$ For stable heart rate image acquisition, the concentration of isoflurane should be further reduced to a minimum of $1-$ $2 \%{ }^{18,19}$ The left ventricular end-systolic posterior wall thickness, left ventricular end-diastolic posterior wall thickness, end-diastolic diameter (LVEDD), end-systolic inner diameter (LVIDd), percentage of left ventricular Ejection fraction $(\mathrm{LVEF} \%)$ and percentage of left ventricular fractional shortening (LVFS\%) were calculated by the ultrasonic system software.

\section{Detection of TNF- $\alpha$ and IL-6 Levels in Heart Tissue by ELISA Method}

After the experimental, $0.1 \mathrm{~g}$ of heart tissue was ground and homogenized in PBS buffer, and then TNF- $\alpha$ and IL-6 were measured in turn in strict accordance with the manufacturer's instructions.

\section{Histopathological Examination of Myocardium}

The fresh cardiac apex was cut into $5 \mathrm{~mm} \times 5 \mathrm{~mm} \times 5 \mathrm{~mm}$ tissue blocks, fixed with 4\% paraformaldehyde, after dehydration with different concentrations of ethanol, paraffin embedding and sectioning were carried out. Then, HE staining, PAS staining, Masson staining and immunohistochemistry (IHC) were performed in different dye solutions. The changes of myocardial cell and myocardial tissue structure, positive material deposition, and the expression of RIP1 and RIP3 were observed under light microscope.

\section{Real-Time Fluorescence Quantitative PCR Was Used to Detect mRNA Levels of RIPI, RIP3 and MLKL in Myocardium}

Operate in strict accordance with the kit for extracting total RNA (Tiangen, China) and cDNA (Invitrogen, USA). Real-Time PCR used an Mx3000 P Detection System (Agilent, USA). The $2-\Delta \Delta^{\mathrm{CT}}$ was used for data analysis, using actin as internal control. The primer sequences are shown in Table 1.

\section{Detection of RIPI, RIP3, MLKL Protein Expressions in Myocardium by Western Blot}

Western blot analysis of myocardial RIP1, RIP3 and MLKL protein expression. ${ }^{27}$ Anti- RIP1 (1:500) antibody, Anti- RIP3 (1:500) antibody and Anti-MLKL (1:1000) antibody and Mouse anti- $\beta$-actin antibody (1:500) were used. Gel imaging system to acquire images.

\section{Statistical Method}

All data statistics were processed by SPSS 25.0 software. The measured data are expressed in terms of mean $\pm \mathrm{SD}$. One way ANOVA was used in each group, $\mathrm{P}<0.05$ was statistically significant.

\section{Results}

\section{Results of Blood Glucose, HW, BW and $\mathrm{HW} / \mathrm{BW}$ in Each Group}

Heart weight (HW) and body weight (BW)decreased with the progression of DM disease, while the HW/BW ratio increased. The HW of rats in $\mathrm{HC} 4 \mathrm{~W}$ was significantly higher than that of CON4W group $(\mathrm{P}<0.01)$, andthe $\mathrm{BW}$ and $\mathrm{HW} / \mathrm{BW}$ ratio were not significant $(\mathrm{P}>0.05)$. $\mathrm{HW}, \mathrm{BW}$ and $\mathrm{HW} / \mathrm{BW}$ ratio were significantly higher in the DM4W group compared with the CON4W group $(\mathrm{P}<0.01)$. The $\mathrm{HW}$ of $\mathrm{DM} 8 \mathrm{~W}$ group was lower than that of DM4W group $(\mathrm{P}<0.01)$, and the HW/BW ratio of DM8W group and IR + DM8W group was significantly increased $(\mathrm{P}<0.01)$, while the BW of DM8W group and IR + DM8W group was significantly decreased. Compared with CON4W group, the $\mathrm{BW}, \mathrm{HW} / \mathrm{BW}$ ratio of DM8W group and Ir+DM8W group were reduced significantly. The HW/BW ratio in Ir+DM8W group was not diffirent compared to the DM8W group, which suggested that irbesartan intervention had little effect on whole heart mass, body mass and heart-body ratio in rats $(\mathrm{P}>0.05)$ (Figure 1).

\section{Result of Cardiac Ultrasound in Each Group}

There was no significant difference in cardiac cavity size and cardiac function between HC4W group and CON4W group ( $\mathrm{P}>0.05$ ). Compared with CON4W and HC4W groups, LVEDD and LVESD were increased, however, LVFS\%, LVEF\% were decreased in DM4W group. LVEDD, LVESD were increased and LVEF\% was decreased significantly $(\mathrm{P}<0.01)$ in $\mathrm{DM} 8 \mathrm{~W}$ group. The LVEF\% was significantly higher in the Ir+DM8W 
A
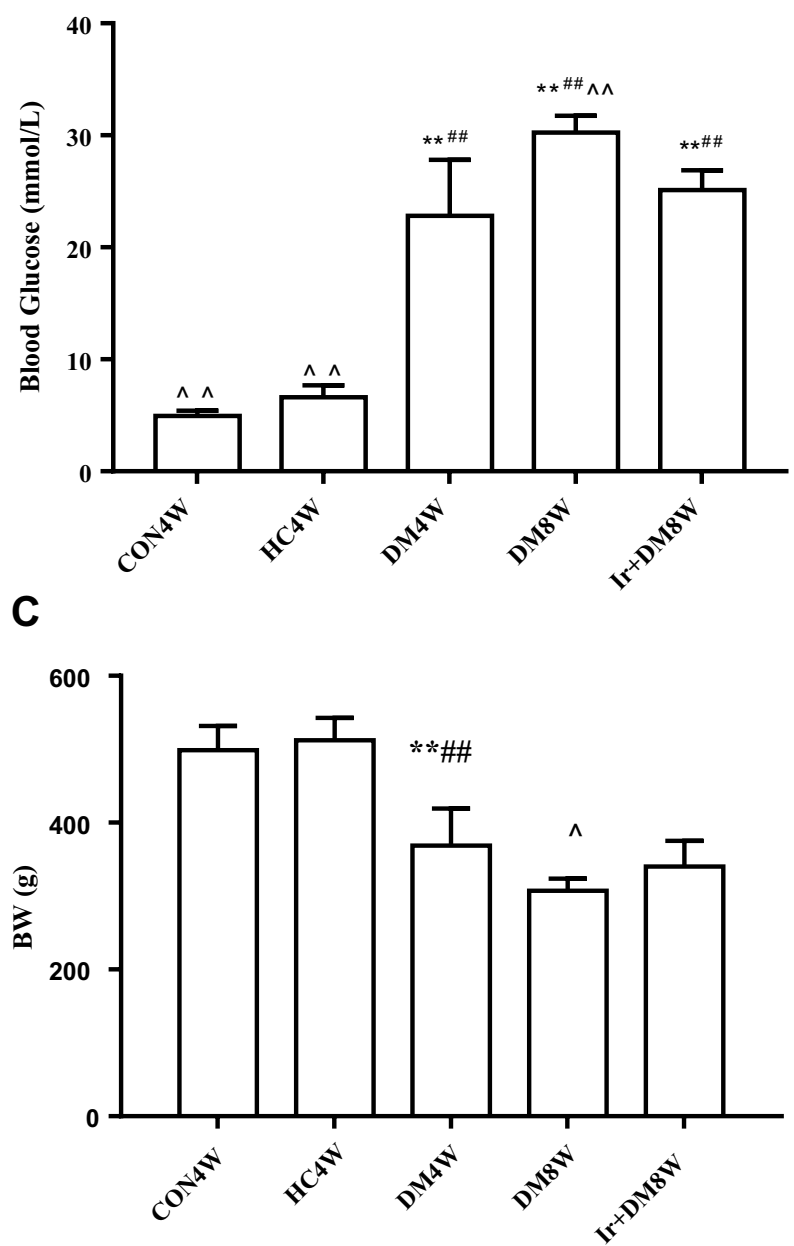

B
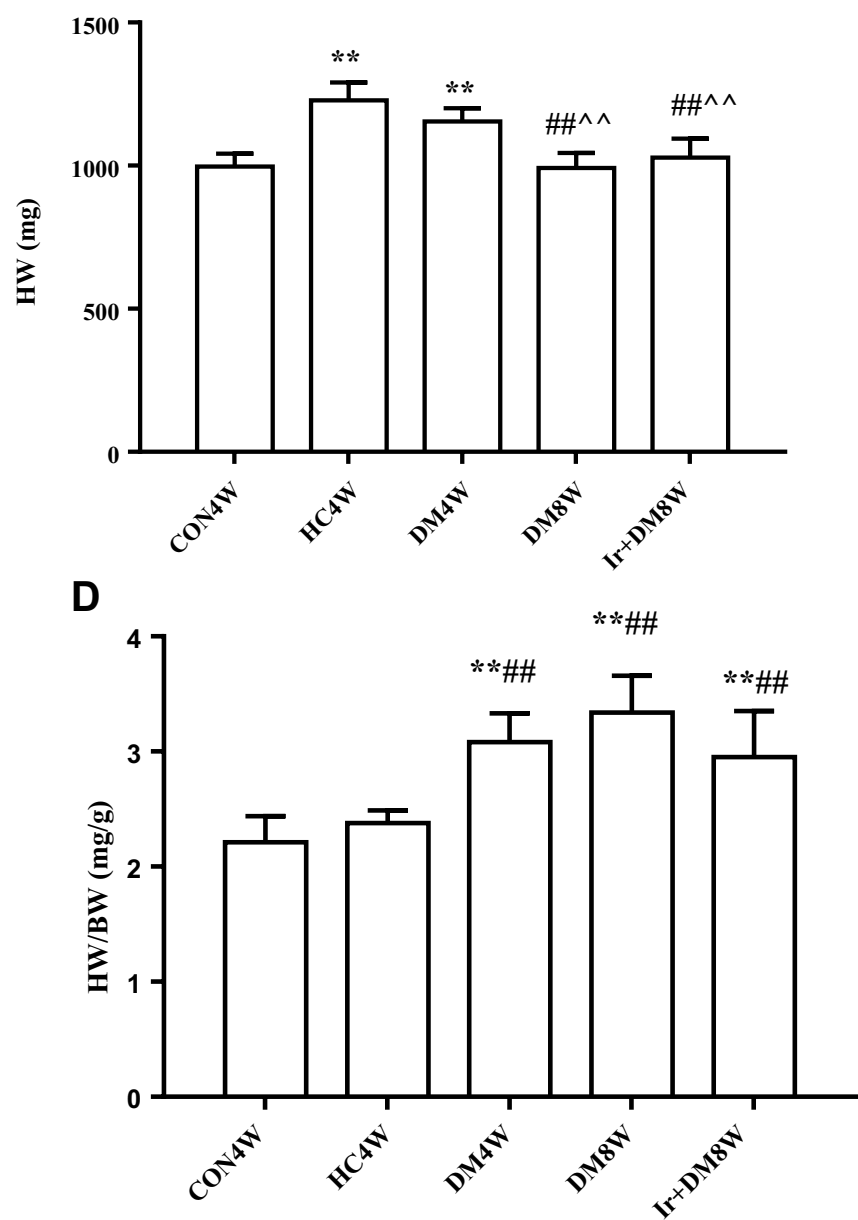

Figure I (A) Comparison of blood glucose in each group (means $\pm S D, n=6)$. (B) Comparison of HW in each group (means $\pm S D$, $n=6$ ). (C) Comparison of $B W$ in each group (means $\pm S D, n=6$ ). (D) Comparison of HW/BW in each group (means $\pm S D, n=6$ ). **P $<0.01$ vs CON4W; ${ }^{\# \prime} \mathrm{P}<0.01$ vs $\mathrm{HC} 4 \mathrm{~W} ;{ }^{\wedge \wedge} \mathrm{P}<0.01$ vs $\mathrm{DM} 4 \mathrm{~W}$.

Abbreviations: CON4W, control 4-week group; HC4W, High calorie 4-week group; DM4W, Diabetic mellitus 4-week group; DM8W, Diabetic mellitus 8-week group; Ir +DM8W, Irbesartan+Diabetes mellitus 8-week group.

intervention group than in the DM8W group $(\mathrm{P}<0.01)$. These findings indicated that irbesartan could delay the deterioration of cardiac function and inhibit ventricular remodeling in diabetic rats (Figure 2).

The Myocardial TNF- $\alpha$ and IL-6 Levels in Each Group

The myocardial TNF- $\alpha$ and IL-6 levels in diabetic rats were increased gradually as the course of disease progression. TNF- $\alpha$ and IL-6 levels in the CON4W group were significantly lower than those in the HC4W, DM4W and DM8W groups $(\mathrm{P}<0.01)$. Although the levels of TNF- $\alpha$ and IL-6 in Ir+DM8W group decreased, they were still higher than those in CON4W group (Figure 3).

\section{HE, PAS, Masson and IHC Staining Results in Rats Myocardium}

The HE staining results indicated that the structure of myocardial tissue in CON4W group was clear, The cardiomyocytes were arranged regularly and the myocardial space was normal. In the $\mathrm{HC}$ group, myocardial tissue was similar as the CON4W group. However, in the DM4W group, the arrangement of cardiomyocytes was disordered, cardiomyocyte hypertrophy and myocardial interstitial widened. The cardiomyocytes in DM8W group were raptured and hypertrophy. In Ir+DM8W group, the arrangement of cardiomyocytes was tight and orderly, and the arrangement of cardiomyocytes was regular, which was improved compared with DM8W (Figure 4A). 
A

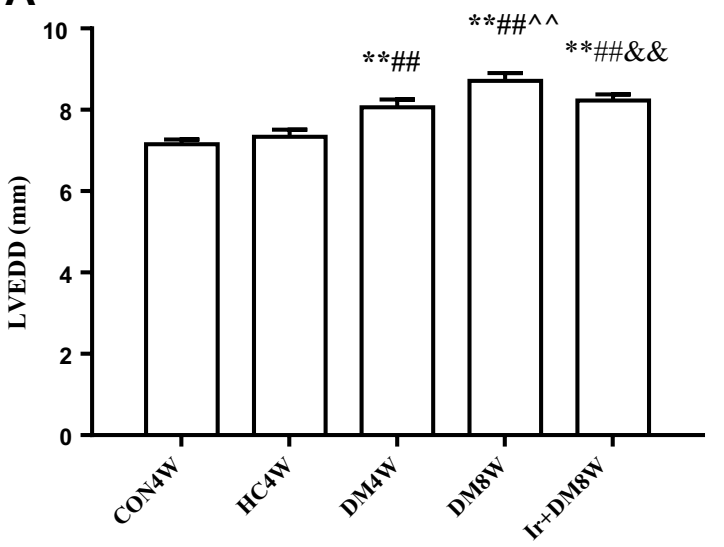

C

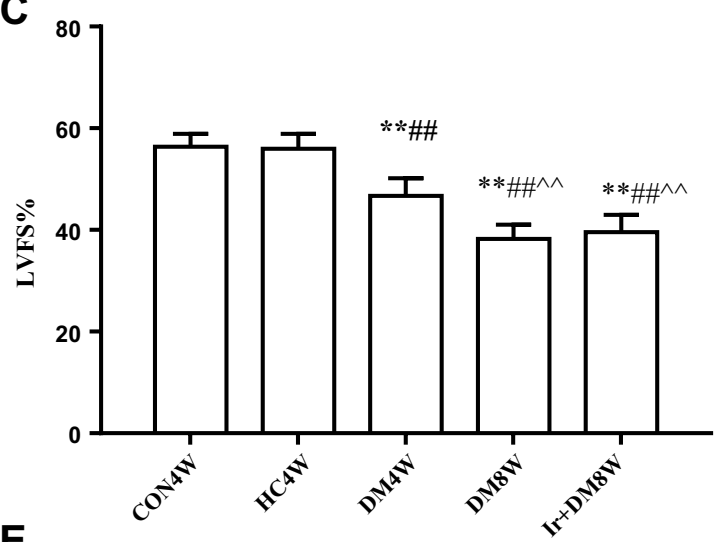

B

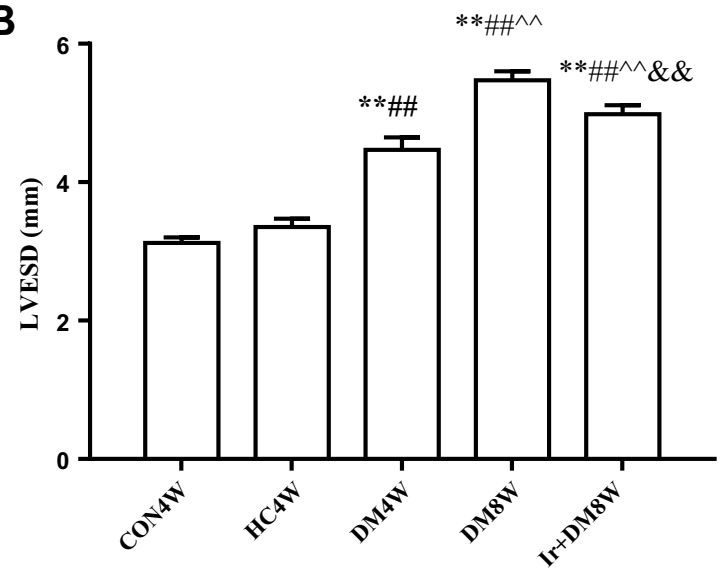

D

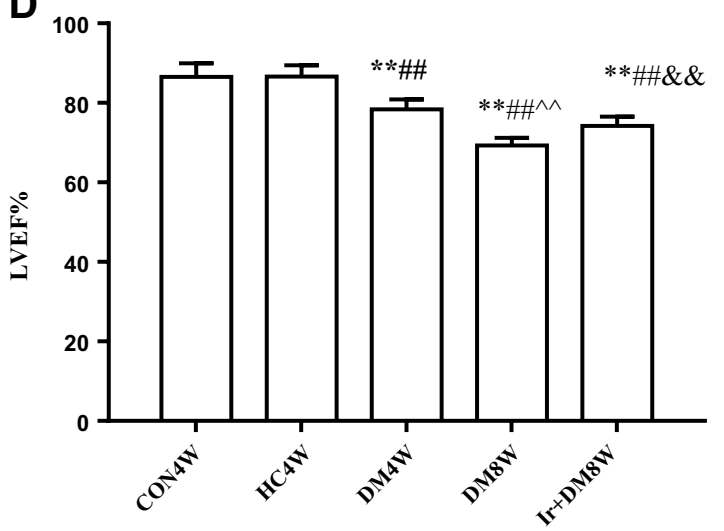

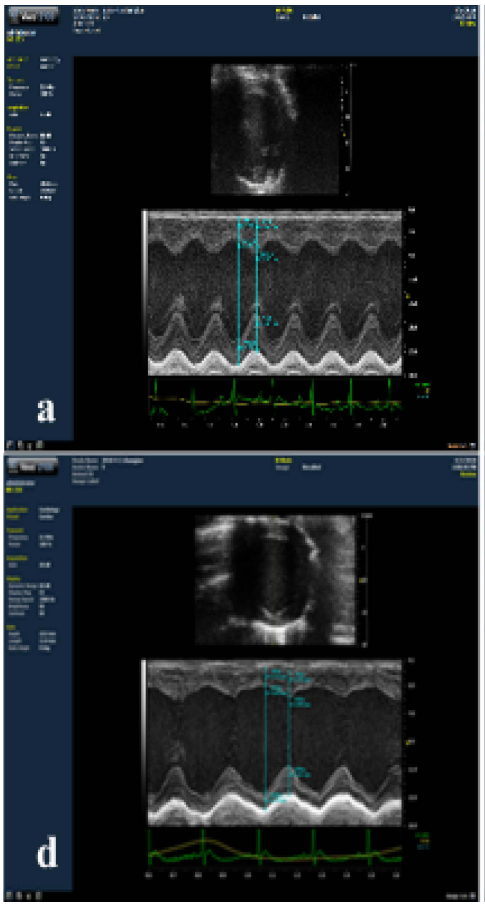
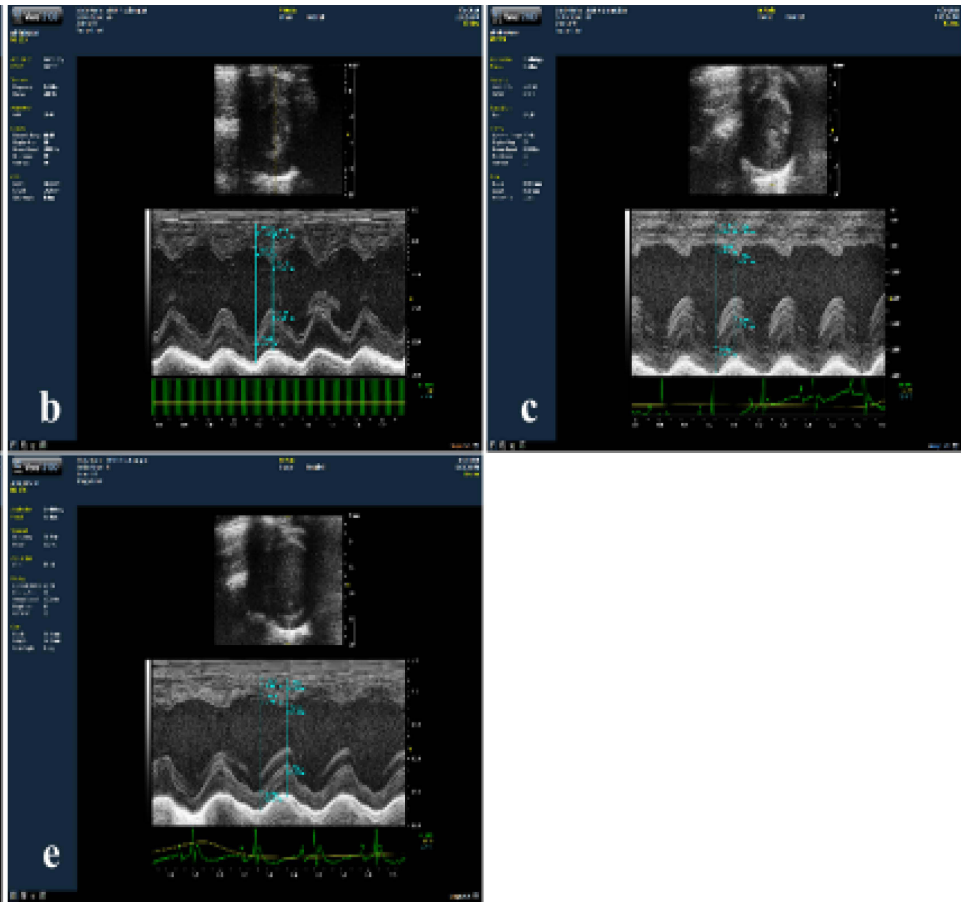

Figure 2 (A) Comparison of LVEDD in each group (mean $\pm S D, n=6$ ). (B) Comparison of LVESD in each group (mean $\pm S D, n=6$ ). (C) Comparison of LVFS\% in each group (mean $\pm S D, n=6$ ). (D) Comparison of LVEF\% in each group (mean $\pm S D, n=6$ ). (E) Changes of cardiac function in each group (mean $\pm S D, n=6$ ). (a) CON4W: control 4-week group; (b) HC4W: High calorie 4-week group; (c) DM4W: Diabetic mellitus 4-week group; (d) DM8W: Diabetic mellitus 8- week group; (e) Ir+DM8W: Irbesartan+Diabetes mellitus 8-week group. ${ }^{* * P}<0.01$ vs CON4W; ${ }^{\#} P<0.01$ vs $H C 4 W ;{ }^{\wedge} P<0.01$ vs $D M 4 W ;{ }^{\& \&} P<0.01$ vs DM8W. 

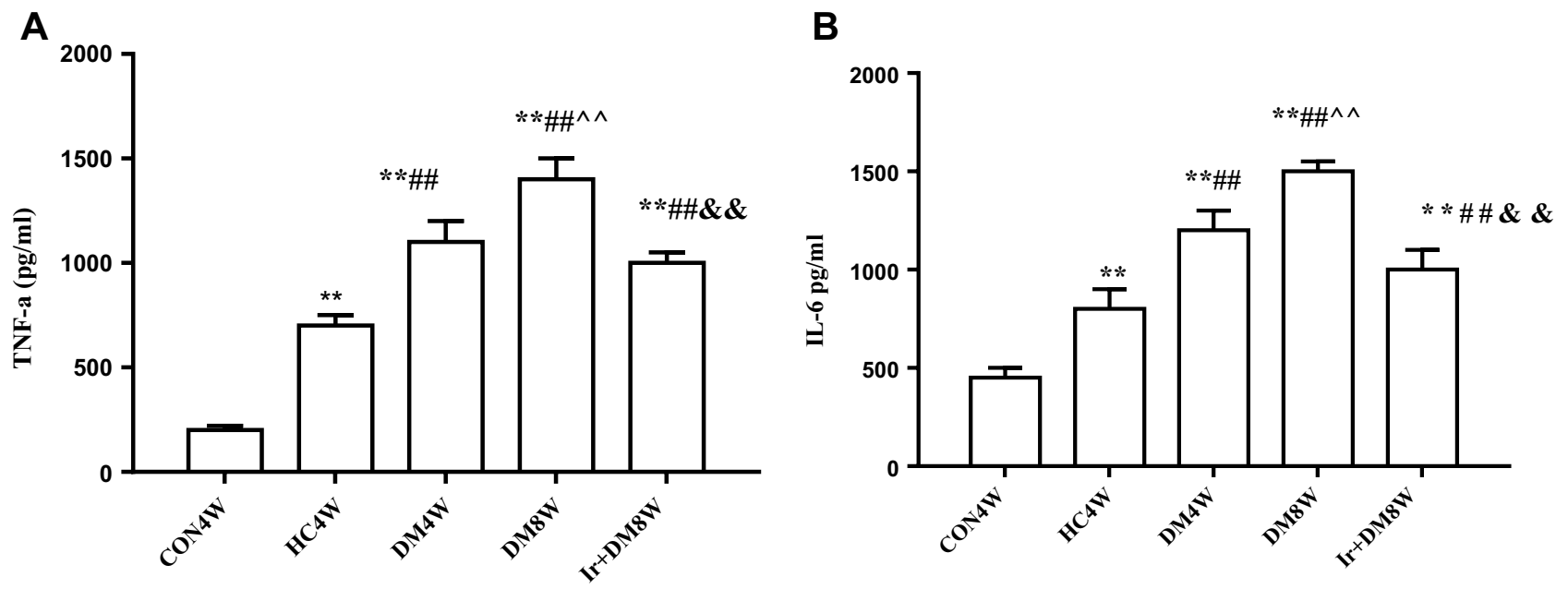

Figure 3 (A) Changes of TNF-a levels of rats myocardial tissue in each group.(means $\pm S D, n=6)$. (B) Changes of IL-6 levels of rats myocardial tissue in each group.(means $\pm \mathrm{SD}, \mathrm{n}=6$ ). ${ }^{* *} \mathrm{P}<0.01$ vs CON4W; ${ }^{\# \#} \mathrm{P}<0.01$ vs HC4W; ${ }^{\wedge} \mathrm{P}<0.01$ vs $\mathrm{DM} 4 \mathrm{~W} ;{ }^{\text {\&\&}} \mathrm{P}<0.0 \mathrm{I}$ vs $\mathrm{DM} 8 \mathrm{~W}$.

The PAS staining results showed that the PAS positive substances in the CON4W and HC4W group were similar. However, in the DM4W and DM8W group the PAS positive substances were significantly increased. Compared with the DM groups, the collagen fiber content and PAS positive substances were significantly reduced in Ir +DM8W group (Figure 4B).

Masson staining results showed regular arrangement of myocardial fibers in the CON4W group, with clear transverse stripes, the collagen fibers are scattered or stringy, and no obvious degeneration or necrosis was observed in myocardial cells. The HC4W group was similar to the CON4W group. In DM4W and DM8W groups, the myocardial fiber arrangement was disordered, the myocardial tissue was destroyed, collagen fibers are coarse, interwoven into a network or stacked in sheets, and a large number of myocardial cells were killed and disintegrated. After irbesartan intervention, the myocardial fiber lesion was significantly improved (Figure 4C).

The positive expressions of RIP1 and RIP3 in IHC were brown-yellow granules in the cytoplasm of cardiomyocytes. The results of CON4W and HC4W were similar, with no or only light yellow staining in cardiomyocytes. With the progression of diabetes, the yellow staining of RIP1 and RIP3 in cardiomyocytes gradually increased, showing a diffuse distribution. The positive expression of RIP1 and RIP3 could be significantly reduced after irbesartan intervention (Figure 4D and E).

\section{The mRNA Expressions of RIPI, RIP3 and} MLKL in Rat Myocardial Tissue

The expression of MLKL mRNA was significantly increased in the HC4W group compared to the CON4W group $(\mathrm{P}<0.01)$, but there was no significant differentiation in RIP1 and RIP3 mRNA expression ( $P>0.05$ ). RIP1, RIP3 and MLKL mRNA expression was significantly increased in the DM4W and DM8W groups compared with the HC4W group $(\mathrm{P}<0.01)$. The expressions of RIP1, RIP3, and MLKL mRNA was significantly decreased in the Ir+DM8W group compared with the DM8W group $(\mathrm{P}<0.01)$. (Figure 5).

\section{The Protein Expressions of RIPI, RIP3 and MLKL in Rat Myocardial Tissue}

Increased expression of RIP1, RIP3 and MLKL protein in $\mathrm{HC} 4 \mathrm{~W}$ and DM4W groups compared with CON4W group (P <0.01). Protein expressions of RIP1, RIP3 and MLKL were increased in the DM8W group compared with CON4W and DM4W groups $(\mathrm{P}<0.01)$. The expression of RIP1, RIP3 and MLKL proteins were reduced in the IR + DM8W group were reduced compared with the DM8W group (P <0.01) (Figure 6).

\section{Discussion}

In this study, we found is that as diabetes progresses, the rat's body weight was decreased gradually, the HW/BW ratio were increased gradually, and the cardiac function became worse accompanied with the aggravation of inflammatory injury which indicated by increases of 
TNF- $\alpha$ and IL-6 levels. At the same time, myocardial fibers and cells were disordered, and the expression of positive substances, RIP1 and RIP3 increased significantly.
The mRNA and protein levels of myocardial RIP1, RIP3 and MLKL increased with the development of DM. After pretreatment of diabetic rats with Irbesartan, which

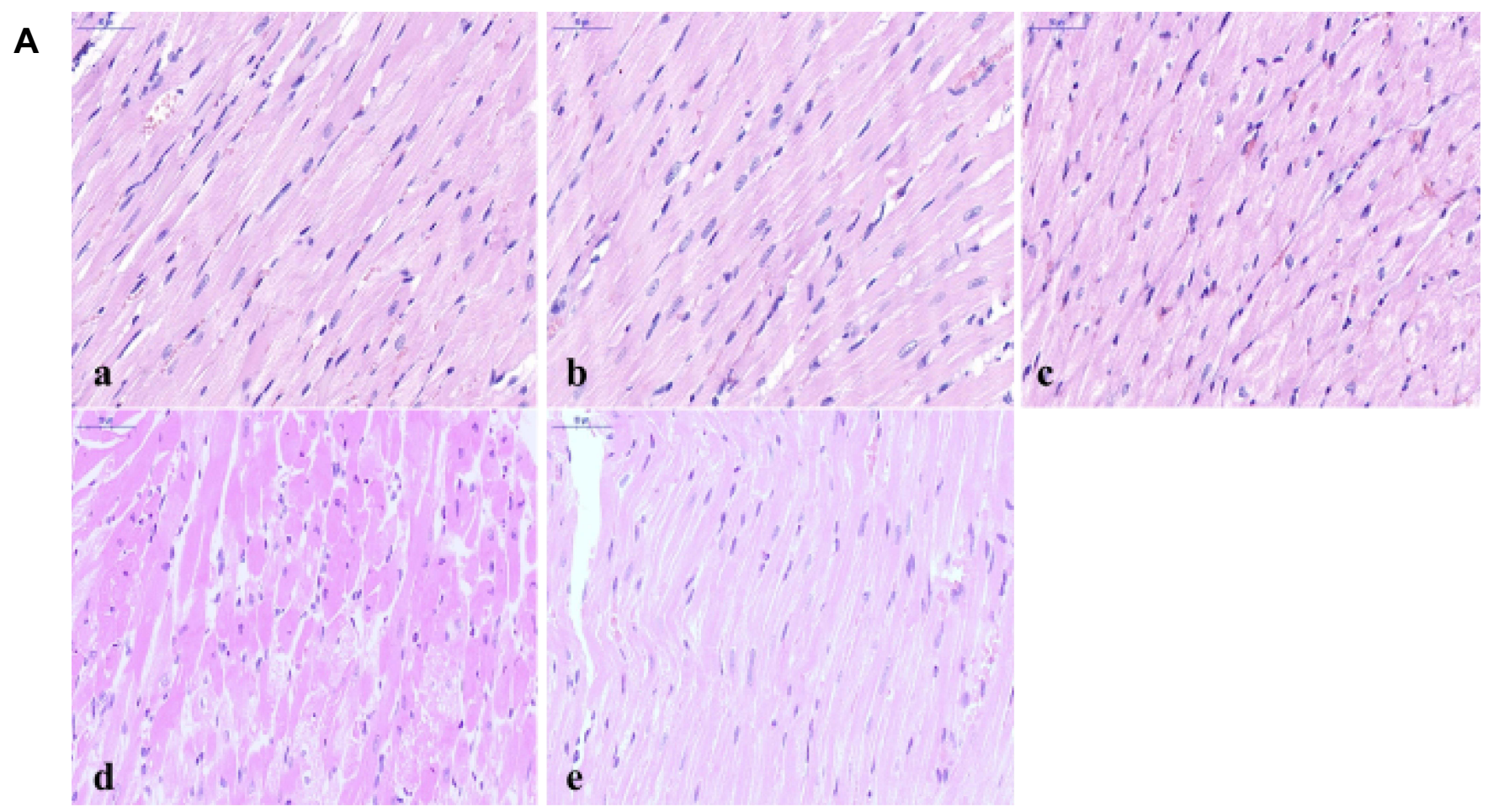

B
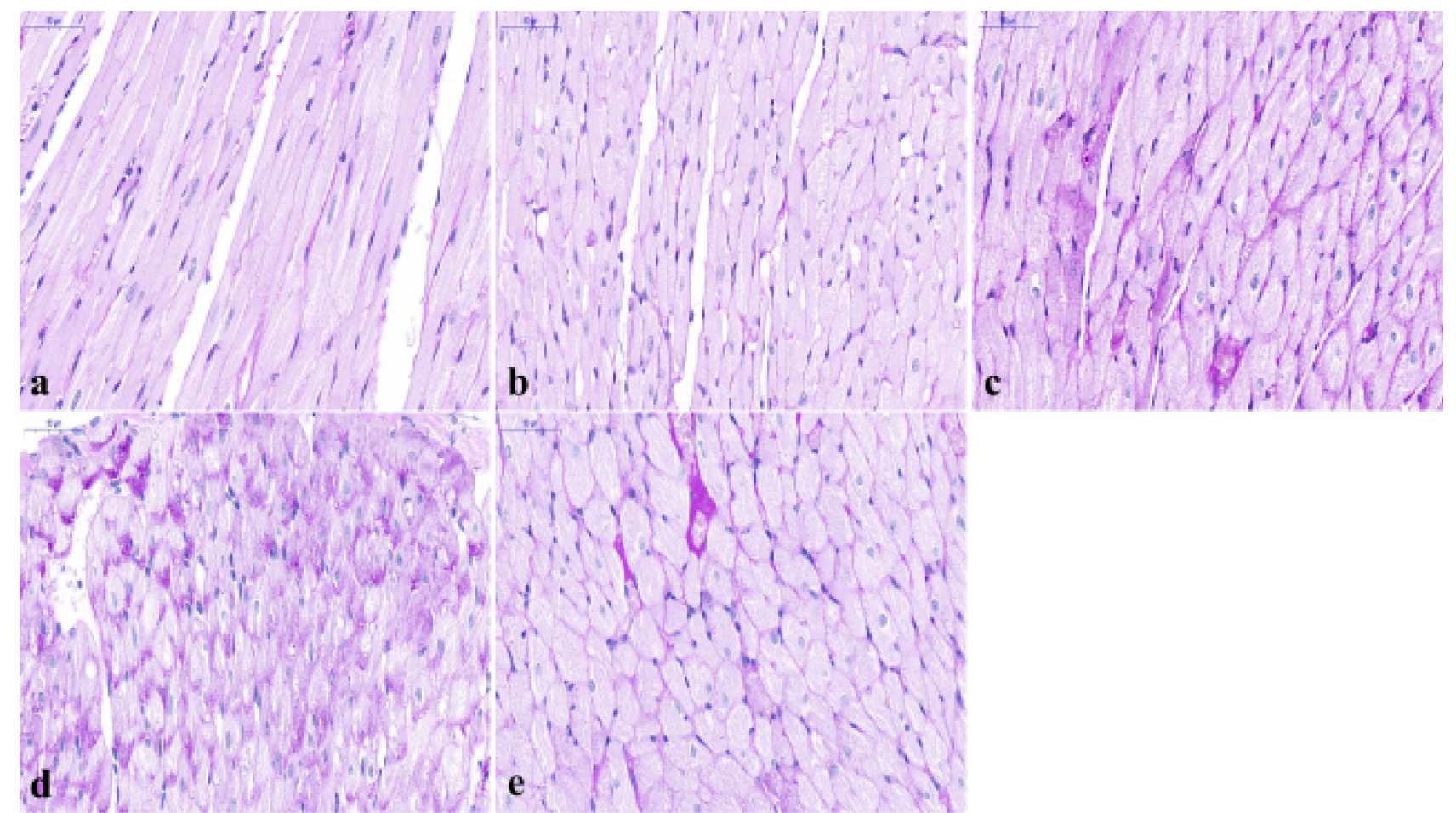

Figure 4 Continue. 


\section{C}

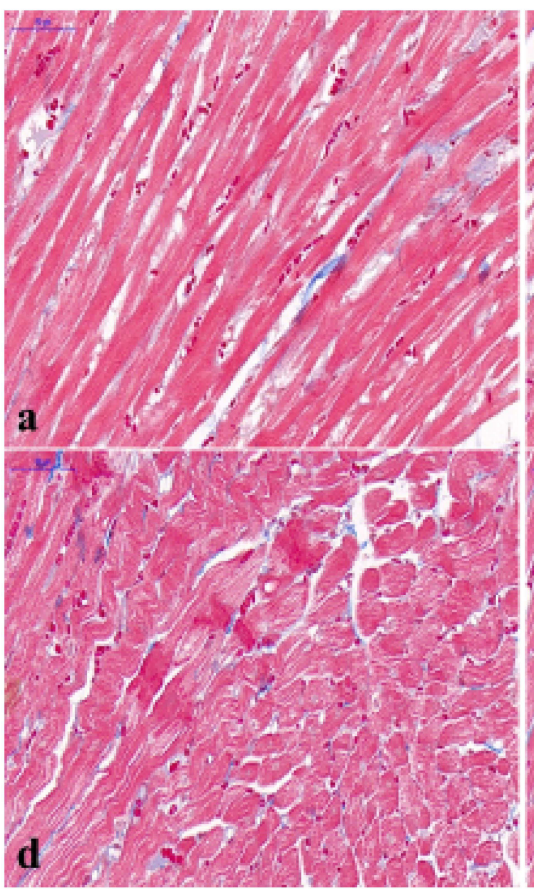

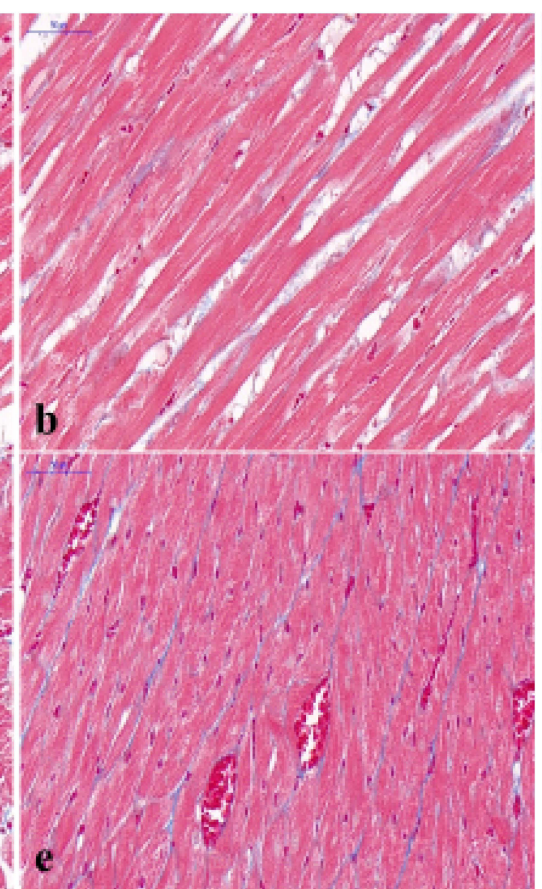

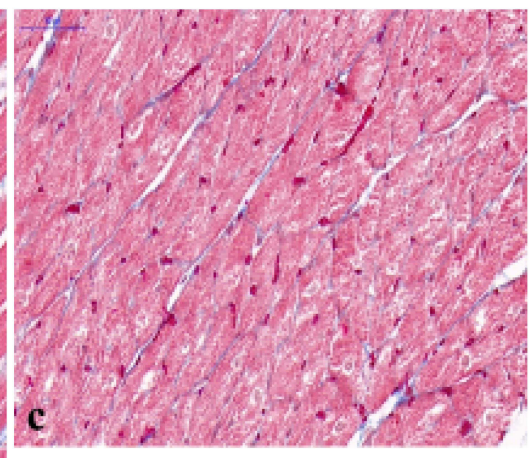

D

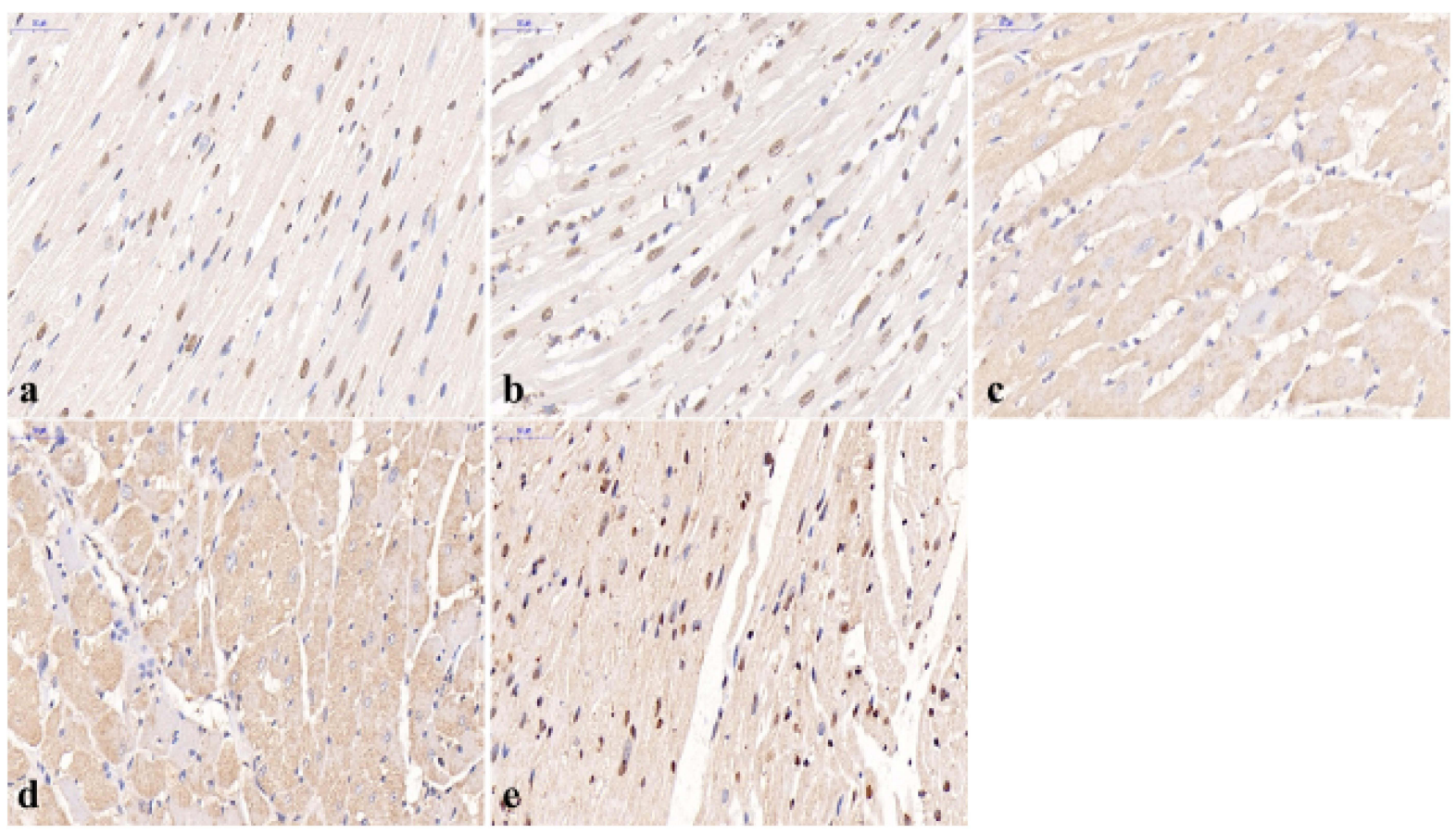

Figure 4 Continue.

inhibits RAS system, the cardiac function was increased, whereas TNF- $\alpha$, IL-6 levels and HW/BW ratio were decreased. Also, the myocardial fibrosis injury was attenuated, and the expression of positive substances, RIP1 and RIP3 were significantly decreased. The reduction of myocardial RIP1, RIP3 and MLKL mRNA and protein levels is related to the effect of Irbesartan. These results suggested that irbesartan has protective effect on myocardial injury of diabetic patients.

Diabetes mellitus (DM) is a group of metabolic disorders that have properties such as lack of insulin or chronically high blood sugar levels. According to the 


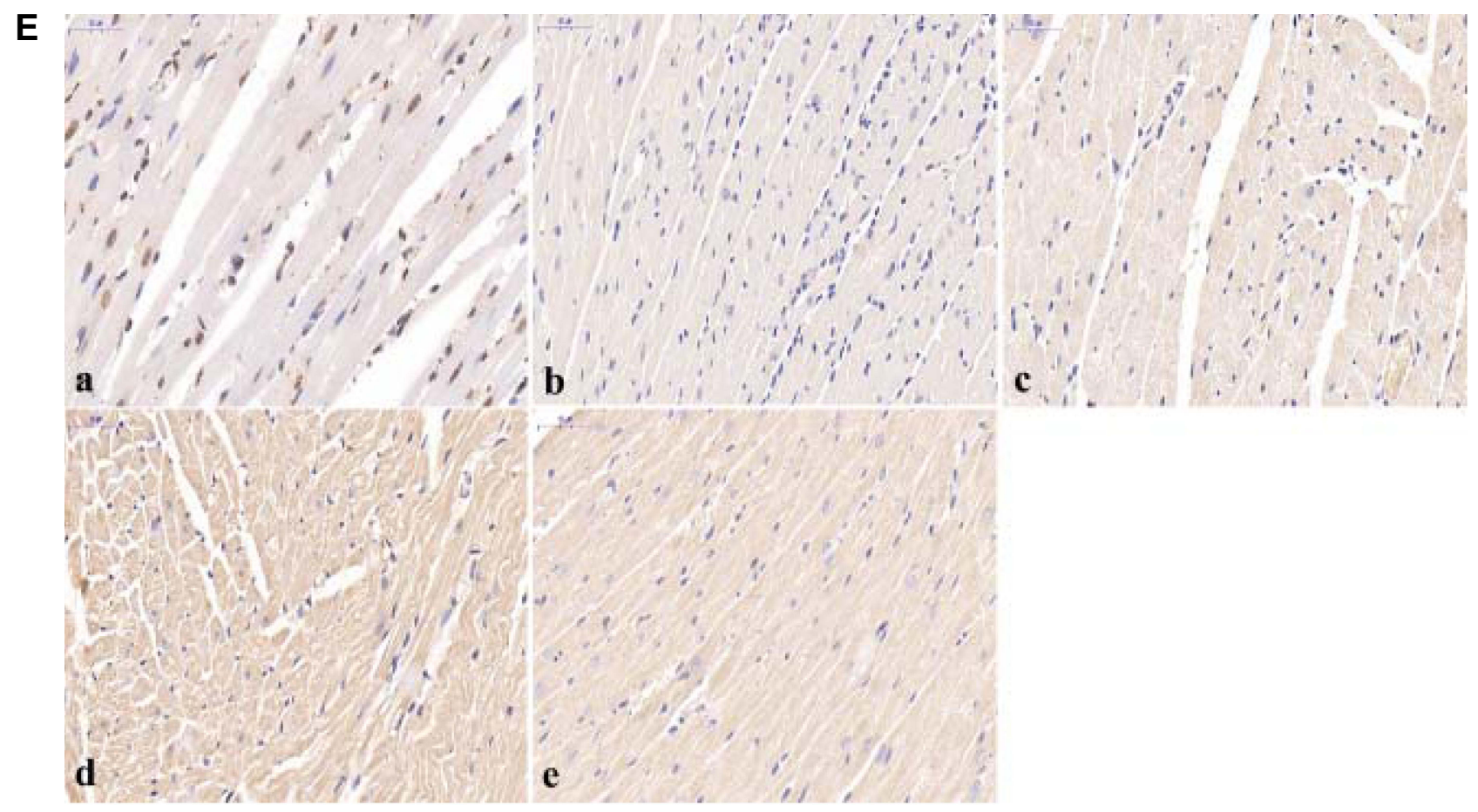

Figure 4 (A) Comparison of HE staining in different groups $(* 400)$. (B) Comparison of PAS staining in myocardial tissue in different groups $(* 400)$. (C) Comparison of Masson staining in cardiac fibers in different groups $(* 400)$. (D) Immunohistochemical expression of RIPI in myocardial cells of each group $(* 400)$. (E) Immunohistochemical expression of RIP3 in myocardial cells of each group (*400). (a) CON4W: control 4-week group; (b) HC4W: High calorie 4-week group; (c) DM4W: Diabetic mellitus 4-week group; (d) DM8W: Diabetic mellitus 8- week group; (e) Ir+DM8W: Irbesartan+Diabetes mellitus 8-week group.

International Diabetes Federation, 415 million people have diabetes. By 2040, that number is expected to rise to 642 million. $^{20}$ In addition, the main complications related to vascular injury include macrovascular and microvascular complications. Merger of cardiovascular disease mortality in the diabetic patients than in diabetic patients complicated with cardiovascular disease 2 to 4 times higher. The pathogenesis of diabetes involves metabolic disorder, myocardial fibrosis and renin-angiotensin system activation. Myocardial fibrosis is one of the complications of diabetes. Its pathological basis is excessive proliferation and structural disorder of myocardial fibroblasts, excessive deposition of myocardial extracellular matrix in myocardial tissue, and the synthesis of a large amount of collagen. ${ }^{21}$ Hyperglycemia is the inducing factor of diabetes, and abnormal lipid metabolism promotes the occurrence of diabetes and its complications. ${ }^{22}$

RAAS activation is an important regulator of fibrosis and a potential target in anti-fibrotic therapy, such as the stimulation of TGF- $\beta 1$ production, enhancement of TGF$\beta 1$ signaling and triggering and differentiation of fibroblast proliferation into collagen secreted myofibroblasts. ${ }^{23}$ And angiotensin II (Ang II) stimulates and mediates the synthesis and collagen secretion of cardiac fibroblasts by binding to angiotensin ii receptors, leading to myocardial fibrosis eventually. However, the exact mechanism of diabetic myocardial fibrosis remains indistinct. As an Ang II receptor inhibitor, irbesartan can play a role in reducing oxidative stress, reducing atherosclerosis plaque formation and alleviating ischemia-reperfusion injury. ${ }^{24}$ Previous studies had shown that Ang II receptor blocker might prevent diabetic cardiomyophy by eliminating Endothelial-mesenchymal transition (EndMT) in diabetic rats, ${ }^{25,26}$ and irbesartan may reduce the level of protein kinase D and endoplasmic reticulum stress, ameliorate the ventricular remodeling in diabetic patients, and significantly reduce the degree of DCM injury and myocardial fibrosis after ibesartan intervention. ${ }^{27,28}$ In our study, after irbesartan intervention LVEDD and LVESD were significantly increased, while LVEF\% and LVFS\% were significantly decreased. The staining results of HE, PAS, Masson and IHC showed that compared with the DM group, the degree of myocardial fibrosis was improved significantly, suggesting that Irbesartan could reduce the occurrence of myocardial fibrosis by inhibiting the binding of AngII to its receptor. 

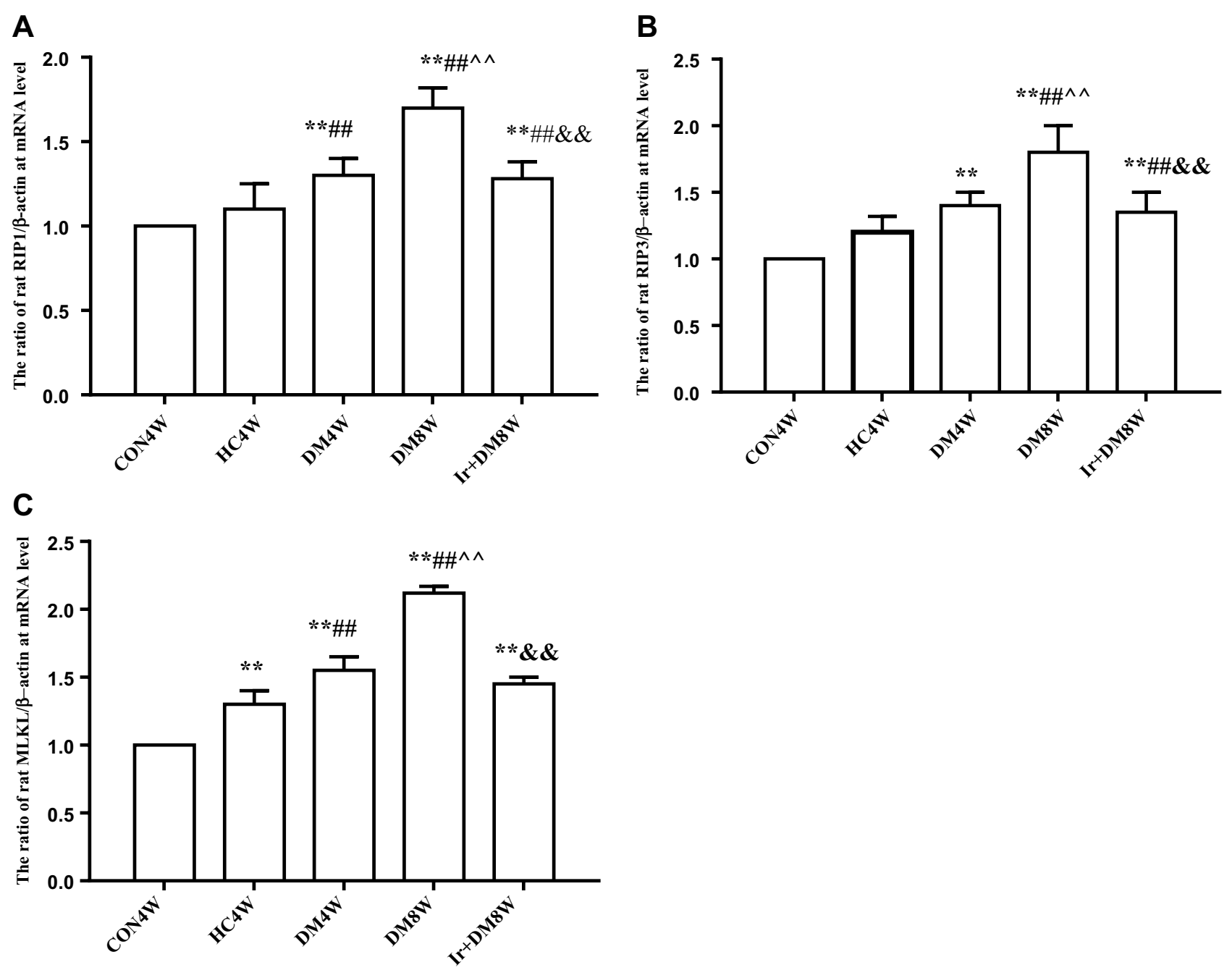

Figure 5 (A) The expressions of RIPI mRNA levels in cardiomyocytes.(means $\pm S D, n=6$ ). (B) The expressions of RIP3 mRNA levels in cardiomyocytes.(means \pm SD, $n=6$ ).

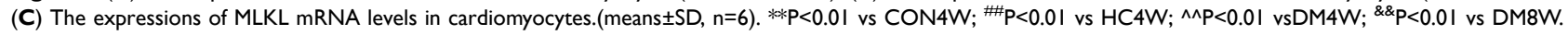

As the important inflammatory factors, TNF- $\alpha$ and IL6 have also been confirmed to be associated with diabetes. ${ }^{29}$ TNF- $\alpha$ is secreted mainly by activated macrophages and is involved in apoptosis and inflammation, it is also as one of the promoters of programmed cell necrosis. ${ }^{30}$ IL-6 is a multi-effect protein secreted by various normal cells and transformed lymphoid and nonlymphocytes, which is involved in various pathological processes in vivo, for instance, autoimmune disorder, inflammation, tumor cell proliferation, etc. ${ }^{31}$ Long-term high glucose state accelerates insulin resistance in cardiomyocytes, and insulin signal transduction is inhibited. Insulin resistance is a low level of proinflammatory state, and the increased fat ratio promotes the release of inflammatory cytokines, such as TNF- $\alpha$ and IL-6. Koçak et al compared the TNF- $\alpha$ and IL- 6 levels between prediabetic and diabetic patients, the results showed that the levels of IL-6 and TNF $-\alpha$ in diabetic patients were significantly higher than those in pre-diabetic patients. ${ }^{32}$ In our study, we observed that the levels of TNF- $\alpha$ and IL- 6 were higher in the diabetic group than that in $\mathrm{CON}$ and $\mathrm{HC}$ groups, and the levels of TNF- $\alpha$ and IL-6 increased with the progression of diabetes. The results showed that the inflammatory reaction was involved in diabetic myocardial injury, and with the prolongation of the course of the disease, the myocardial injury was aggravated, and the levels of TNF- $\alpha$ and IL- 6 were gradually increased.

Necroptosis is a mode of cell death with the characteristics of cell precise regulation, which is regulated by RIP1, RIP3 and MLKL complex, ${ }^{33,34}$ among these factors, RIP3 is the downstream of RIP1, when RIP1 combines with RIP3, the complex can induce MLKL phosphorylation, leading to 


\section{A}
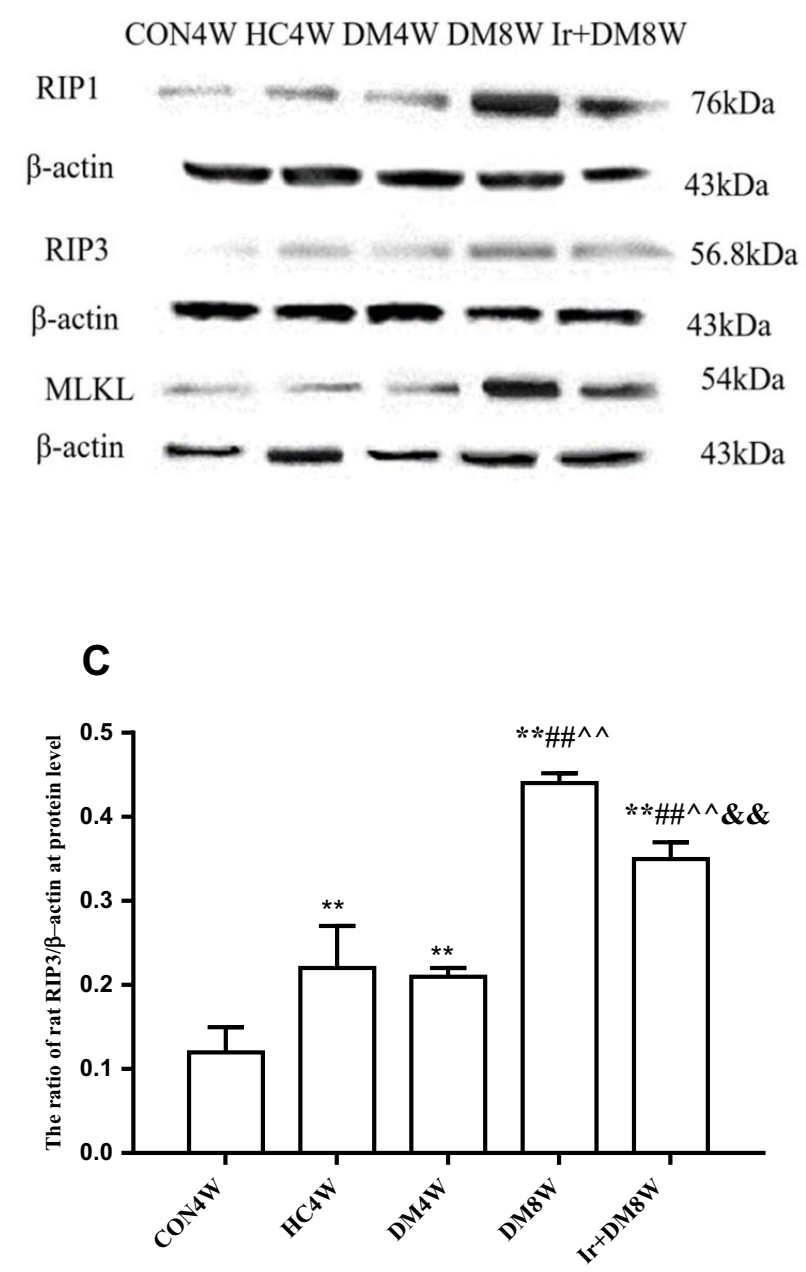

B

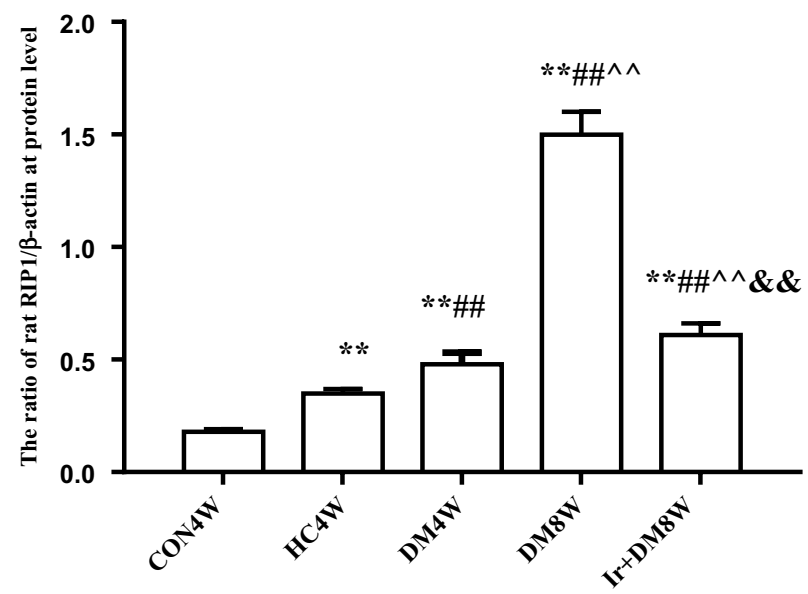

D

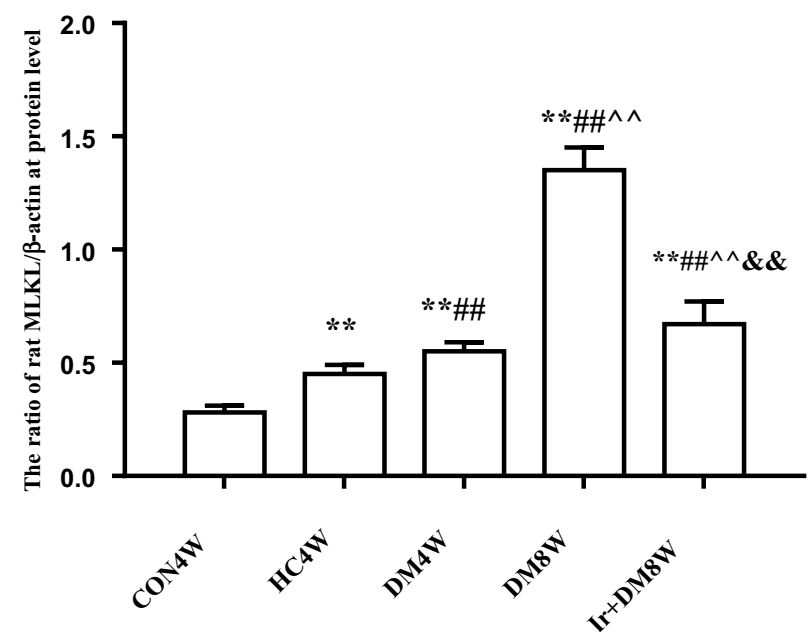

Figure 6 (A) Typical bands of proteins in the Western blot experiment (means $\pm S D, n=6)$. (B) The ratio of RIPI protein levels in cardiomyocytes (means \pm SD, $n=6$ ). (C) The ratio of RIP3 protein levels in cardiomyocytes (means $\pm S D, n=6)$. (D) The ratio of MLKL protein levels in cardiomyocytes (means $\pm S D, n=6)$. **P<0.0I vs CON4W, ${ }^{\# \#<0.01}$ vs $\mathrm{HC} 4 \mathrm{~W}, \wedge \wedge \mathrm{P}<0.01$ vsDM4W, ${ }^{\& \&} \mathrm{P}<0.01$ vs $\mathrm{DM} 8 \mathrm{~W}$.

the transfer of necrosome to the cell membrane, increases the plasma membrane permeability and damage-associated molecular pattern (DAMPs) release, induces the releases of many inflammation factors, meanwhile, it can induce the destruction of mitochondria and other organelles, finally leads to cell death ${ }^{35,36}$. So necroptosis is an important cell death mode in disease condition, the necroptosis pathway can be regarded as a therapeutic target. $\mathrm{Xu}$ et al believed that MLKL as a regulator of insulin sensitivity, could be a potential therapeutic target for insulin resistance and DM, inhibition of MLKL or other key necroptosis regulators could increase liver insulin sensitivity and improve metabolic disorder caused by obesity. Therefore, this study attempted to determine whether RIP1, RIP3, MLKL expression were altered during the development and progression of diabetes, and to explore the role of irbesartan in a diabetic model. In a previous study, we have observed that in high glucose induced primary cardiomyocytes injury model, the expressions of RIP1, RIP3 and MLKL were elevated, and activation of ALDH2 prevented the happing of necroptosis and restraining of oxidative stress and inflammation. ${ }^{37}$ In this experiment, diabetic rats were taken as the research object. It has been observed that during the development of diabetes, the myocardial tissue fibers and cells were disordered and a large amount of collagen fibers were proliferated, in the progression of diabetes, the mRNA and protein levels of myocardial RIP1, RIP3 and MLKL were increased, suggesting necroptosis plays a crucial part in myocardial injury. When ibesartan was given in the diabetes model, RIP1, RIP3 and MLKL expressions were reduced, TNF- $\alpha$ and IL-6 were also 
reduced, which indicating that irbesartan could reduce inflammation and improve ventricular remodeling.

There are some limitations in this study. We just observed the changes of RIP1, RIP3, MLKL and inflammatory factors, and we will explore its pathogenesis in depth in the future.

In conclusion, in our study, necroptosis is involved in the process of diabetic myocardial injury, irbesartan may play a protective role in myocardium by regulating this pathway. It is very important to understand the role of cell death signaling pathway in the occurrence and development of cardiomyopathy for the discovery of new DCM targeted therapeutic drugs and biomarkers.

\section{Data Sharing Statement}

Data supporting the findings can be obtained by contacting the corresponding author.

\section{Ethical Approval}

The Medical Ethics Committee of Bengbu Medical College has passed the ethics examination and approval. The reference number is as follows: [2017] number 075.

\section{Acknowledgments}

The present study was funded by the National Natural Science Foundation of China (81770297, 81970313), Anhui Province Fund for Excellent University Talents (gxyq2020022), Anhui Province Natural Foundation (Grant nos. 1908085QH353), Anhui Province Fund for Excellent University Talents (1804h08020246), and Postgraduate Innovation Program of Bengbu Medical College (Byycx1918).

\section{Disclosure}

The authors declare no conflicts of interest for this work.

\section{References}

1. Cao RP, Fang D, Wang JH, et al. ALDH2 overexpression alleviates high glucose-induced cardiotoxicity by inhibiting NLRP3 inflammasome activation. J Diabetes Res. 2019;2019:4857921.

2. Masuda T, Muto S, Fujisawa G, et al. Heart angiotensin II-induced cardiomyocyte hypertrophy suppresses coronary angiogenesis and progresses diabetic cardiomyopathy. Amn J Physiol Heart Circ Physiol. 2012;302(9):H1871-H1883. 2011 doi:10.1152/ajpheart.00663.

3. Tan Y, Li XK, Prabbu SD, et al. Angiotensin II plays a critical role in alcohol-induced cardiac nitrative damage, cell death, remodeling, and cardiomyopathy in a protein kinase C/nicotinamide adenine dinucleotide phosphate oxidase-dependent manner. J Am Coll Cardiol. 2012;59 (16):1477-1486. doi:10.1016/j.jacc.2011.12.034
4. Rani N, Bharti S, Bhatia J, Nag TC, Ray R, Arya DS. Chrysin, a PPAR- $\gamma$ agonist improves myocardial injury in diabetic rats through inhibiting AGE-RAGE mediated oxidative stress and inflammation. Chem Biol Interact. 2016;250:59-67. doi:10.1016/j.cbi.2016.03.015

5. Hotamisligil GS. Inflammation and metabolic disorders. Nature. 2017;542(7640):177-185. doi:10.1038/nature21363

6. Dong B, Yu QT, Dai HY, et al. Angiotensin-converting enzyme-2 overexpression improves left ventricular remodeling and function in a rat model of diabetic cardiomyopathy. $J$ Am Coll Cardiol. 2012;59 (8):739-747. doi:10.1016/j.jacc.2011.09.071

7. Thomas CM, Yong QC, Rosa RM, et al. Cardiac- specific suppression of $\mathrm{NF}-\mathrm{\kappa B}$ signaling prevents diabetic cardiomyopathy via inhibition of the reninangiotensin system. Am J PhysiolHeart Circ Physiol. 2014;307(7): H1036-H1045. doi:10.1152/ajpheart.00340.2014

8. Rong L, Sun S, Zhu F, et al. Effects of irbesartan on myocardial injury in diabetic rats: the role of NLRP3/ASC/Caspase-1 pathway. $J$ Renin Angiotensin Aldosterone Syst. 2020;21(2):1470320320 926049. doi:10.1177/1470320320926049

9. Li QF, Yang JK, Lai XY, et al. Clinical guidelines for the prevention and treatment of diabetic renal diseases in China. Chin J Diabetes. 2019;11(1):15-28.

10. Ren X, Guan G, Liu G, Liu G. Irbesartan ameliorates diabetic nephropathy by reducing the expression of connective tissue growth factor and alpha-smooth-muscle actin in the tubulointerstitium of diabetic rats. Pharmacology. 2009;83(2):80-87. doi:10.1159/000180123

11. Iskender H, Dokumacioglu E, Sen TM, Ince I, Kanbay Y, Saral S. The effect of hesperidin and quercetin on oxidative stress, NF- $\mathrm{KB}$ and SIRT1 levels in a STZ-induced experimental diabetes model. Biomed Pharmacother. 2017;90:500-508. doi:10.1016/j. biopha.2017.03.102

12. Lee HW, Lee SJ, Lee MY, et al. Enhanced cardiac expression of two isoforms of matrix metalloproteinase-2 in experimental diabetes mellitus. PLoS One. 2019;14(8):e0221798. doi:10.1371/journal.pone. 0221798

13. Li L, Chen Y, Doan J, Murray J, Molkentin JD, Liu Q. Transforming growth factor $\beta$-activated kinase 1 signaling pathway critically regulates myocardial survival and remodeling. Circulation. 2014;130 (24):2162-2172. doi:10.1161/CIRCULATIONAHA.114.011195

14. Kaiser WJ, Haripriya S, Huang CZ, et al. Toll-like receptor 3-mediated necrosis via TRIF, RIP3, and MLKL. Biol Chem. 2013;288(43):31268-31279. doi:10.1074/jbc.M113.462341

15. Mompeán M, Li W, Li JX, et al. The structure of the necrosome RIPK1-RIPK3 core, a human hetero-amyloid signaling complex. Cell. 2018;173(5):1244-1253.e10. doi:10.1016/j.cell.2018.03.032

16. James MM, John S. Ars Moriendi; the art of dying well-new insights into the molecular pathways of necroptotic cell death. EMBO Rep. 2014;15(2):155-164. doi:10.1002/embr.201337970

17. Xu H, Du X, Liu G, et al. The pseudokinase MLKL regulates hepatic insulin sensitivity independently of inflammation. Mol Metab. 2019;23:14-23. doi:10.1016/j.molmet.2019.02.003

18. Grune J, Ritter D, Krater K, et al. Accurate assessment of LV function using the first automated 2D-border detection algorithm for small animals-evalution to models of LV dysfunction. Cardiovasc Ultrasound. 2019;17(1):7. doi:10.1186/s12947-019-0156-0

19. Wilck N, Marko L, Blogh A, et al. Nitric oxide-sensitive guanylyl cyclse stimulation improves experimental heart failure with preserved ejection fraction. JCI Insight. 2018;3(4):e96006. doi:10.1172/jci. insight. 96006

20. Tomas A, Jones B, Leech C. New insights into beta-cell GLP-1 receptor and cAMP signaling. J Mol Biol. 2020;432(5):1347-1366. doi:10.1016/j.jmb.2019.08.009

21. Martos R, Baugh J, Ledwidge M, et al. Diastolic heart failure: evidence of increased myocardial collagen turnover linked to diastolic dysfunction. Circulation. 2007;115(7):888-895. doi:10.1161/ CIRCULATIONAHA.106.638569 
22. Guo DF, Sun YL, Hamet P, Inagami T. The angiotensin II type 1 receptor and receptor-associated proteins. Cell Res. 2001;11 (3):165-180. doi:10.1038/sj.cr.7290083

23. Frangogiannis NG. Cardiac fibrosis cell biological mechanisms, molecular pathways and therapeutic opportunities. Mol Aspects Med. 2019;65:70-99.

24. Yan Z, Ayahisa W, Songji Z, et al. Suppressive effects of Irbesartan on inflanmmation and apoptosis in atherosclerotic plaques of apoE/ Mice: molecular imaging with $14 \mathrm{C} / \mathrm{FDG}$ and 99m Tc, Annexin A5. PLosOne. 2014;9(2):e89338. doi:10.1371/journal.pone.0089338

25. Abraham HM, White CM, White WB. The comparative efficacy and safety of the angiotensin receptor blockers in the management of hypertension and other cardiovascular diseases. Drug Saf. 2015;38 (1):33-54. doi:10.1007/s40264-014-0239-7

26. Aneja A, Tang WHW, Bansilal S, et al. Diabetic cardiomyopathy: insights into pathogenesis, diagnostic challenges, and therapeutic options. Am J Med. 2008;121(9):748-757. doi:10.1016/j.amjmed.20 08.03.046.

27. Liu X, Xu Q, Wang XM, et al. Irbesartan ameliorates diabetic cardiomyopathy by regulating protein kinase D and ER stress activation in a type 2 diabetes rat model. Pharmacol Res. 2015;93:43-51. doi:10.1016/j.phrs.2015.01.001

28. Tang RN, Lv LL, Zhang JD, et al. Effects of angiotensin II receptor blocker on myocardial endothelial-to-mesenchymal transition in diabetic rats. Int J Cardiol. 2013;162(2):92-99. doi:10.1016/j.ijcard.20 11.06.052

29. Díaz-Soto G, de Luis DA, Conde-Vicente R, et al. Beneficial effects of liraglutide on adipocytokines, insulin sensitivity parameters and cardiovascular risk biomarkers in patients with Type 2 diabetes: a prospective study. Diabetes Res Clin Pract. 2014;104(1):92-96. doi:10.1016/j.diabres.2014.01.019
30. Vanlangenakker N, Vanden Berghe T, Vandenabeele P. Many stimuli pull the necrotic trigger, an overview. Cell Death Differ. 2012;19 (1):75-86. doi:10.1038/cdd.2011.164

31. Alegria GC, Boukhlal S, Cornec D, et al. The pathophysiology of polymyalgia rheumatica, small pieces of a big puzzle. Autoimmun Rev. 2020;19(11):102670. doi:10.1016/j.autrev.2020.102670

32. Koçak H, Oner-Iyidoğan Y, Gürdöl F, et al. Advanced oxidation protein products in obese women: its relation to insulin resistance and resistin. Clin Exp Med. 2007;7(4):173-178. doi:10.1007/s10238007-0143-x

33. Petrie EJ, Czabotar PE, Murphy JM, et al. The structural basis of necroptotic cell death signaling. Trends Biochem Sci. 2019;44 (1):53-63. doi:10.1016/j.tibs.2018.11.002

34. Zhang L, Feng Q, Wang T, et al. Necrostatin-1 protects against paraquat-induced cardiac contractile dysfunction via RIP1-RIP3MLKL-dependent necroptosis pathway. Cardiovasc Toxicol. 2018;18(4):346-355. doi:10.1007/s12012-017-9441-z

35. Ding W, Shang L, Huang JF, et al. Receptor interracting protein 3-induced RGC-5 cell necroptosis following oxygen glucose deprivation. BMC Neurosci. 2015;16(1):49. doi:10.1186/s12868015-0187-x

36. Ni HM, Chao X, Kaseff J. Receptor-interracting serine/threonine kinase 3(RIP3)-mixed lineage kinase like protein (MLKL)-mediated necroptosis contributes to Ischemia-Reperfusion injury of steatotic livers. AM J Pathol. 2019;189(7):1363-1374. doi:10.1016/j.ajpath.20 19.03 .010

37. Pin FK, Jia HW, Dian F, et al. Activation of ALDH2 attenuates high glucose induced rat cardiomyocyte fibrosis and necroptosis. Free Radic Biol Med. 2020;146:198-210. doi:10.1016/j.freeradbiomed.20 19.10.416

Diabetes, Metabolic Syndrome and Obesity: Targets and Therapy

Dovepress

\section{Publish your work in this journal}

Diabetes, Metabolic Syndrome and Obesity: Targets and Therapy is an international, peer-reviewed open-access journal committed to the rapid publication of the latest laboratory and clinical findings in the fields of diabetes, metabolic syndrome and obesity research. Original research, review, case reports, hypothesis formation, expert opinion and commentaries are all considered for publication. The manuscript management system is completely online and includes a very quick and fair peer-review system, which is all easy to use. Visit http://www.dovepress.com/testimonials.php to read real quotes from published authors.

Submit your manuscript here: https://www.dovepress.com/diabetes-metabolic-syndrome-and-obesity-targets-and-therapy-journal 